\title{
A comparison of morphology and physical properties of microdiamonds from the mantle and crustal environments
}

\author{
Shatsky V.S. ${ }^{1}$, Zedgenizov D.A. ${ }^{1}$, Yefimova E.S. ${ }^{1}$, Rylov G.M. ${ }^{1}$, De Corte K. ${ }^{2}$, Sobolev N.V. ${ }^{1}$ \\ 1.United Institute of Geology, Geophysics and Mineralogy, Novosibirsk 630090, Russia \\ 2.Royal Museum for Central Africa, Department of Geology and Mineralogy, Steenweg op Leuven 13, B-3080 Terwuren, \\ Belgium
}

Microdiamonds from the Udachnaya and Sytykanskaya kimberlite pipes $(<1 \mathrm{~mm})$ as well as diamonds from metamorphic rocks $(10-300 \mu \mathrm{m})$, alluvial placers of the Kokchetav Massif $(60-340 \mu \mathrm{m})$, and alluvial placers in Western Australia $(100-200 \mu \mathrm{m})$ have been examined by. FTIR-spectroscopy, cathodoluminescence, X-ray topography, and scanning electron microscopy.

All morphological types specific for diamonds from kimberlites occur among metamorphogeneous diamonds. There are sharp-edge octahedral crystals, cubo-octahedra, cuboids, coated diamonds, twinned crystals, and aggregates. Variations in crystal morphology are established not only within one specimen but also, in some cases, in a single aggregate, with the complete series of octahedron-to-cuboid transient forms observed. At the same time, crystals of a certain habit are predominant in some types of rocks. In particular, for Kokchetav massif pyroxene-carbonate rocks and garnet pyroxenites are characterized by cuboids, while cataclastic biotite gneisses, by cubo-octahedral crystals. The most widespread morphological type among the crystals of the Orlinogorsk placer from the northern part of Kokchetav Massif and alluvial placers in Western Australia is cuboid ( $30 \%)$. Unlike the crystals from metamorphic rocks, the placer diamonds are dominated by dodecahedroids. Octahedral crystals are rare. Rounded crystals are predominant among single crystals from the Udachnaya and Sytykanskaya kimberlite pipes (Fig.1). The crystals of this group are subdivided into octahedroids, tetrahexahedroids, and dodecahedroids. Octahedral crystals without traces of dissolution are scarce. The octahedral crystals often have additional faces, blunting the octahedron edges; they correspond to various simple shapes, such as rhombic dodecahedron and trigonotrioctahedron. Cuboids represent the most rare group of crystals (Fig.1).

Zoning is established for all crystal varieties. The most CL-images show stratigraphic bandings parallel to $\{111\}$ in octahedrons. Two distinct zones are recognized most often. As a rule, there is a brightluminescent zone in the center, with the step-wise bandings or, more rarely, stratigraphic bandings. Sometimes the central part is of block-mosaic structure. The outer zone (about one fifth of the crystal thickness) reflects X-rays much weaker than the inner zones, and this indicates that the outer zone is much more perfect. In rare cases, cross pattern are obsereved at the central portion of crystal. Also there were microdiamonds with cubic shape of central zone.Fibrous structure of this zone was established by $\mathrm{X}$-ray topography. The further evolution of the form of crystal growth gives evidence of the cuboid-tooctahedral transformation.

The central core is also observed in an octahedral from the Kokchetav zoisite gneiss, despite its small size $(30 \mu \mathrm{m})$. The crystal has an imperfect structure with a high density of dislocations. The X-ray section topograph taken in various reflections show that the crystal volume is mostly occupied by cuboid growth sectors.

Like the octahedral crystals, the rounded ones from kimberlite pipes, described as dodecahedroids, often show the stratigraphic bandings parallel to $\{111\}$, however, less distinctly on CL images. Sometimes 
several zones with rounded boundaries are distinctly visible. Observed in the octahedrons, the peripheral zone is not seen in the dodecahedroids.. In crossed nicols, dodecahedroids often exhibit a specific 'tatami' as a result from plastic deformation. Either severely distorted or damaged, a smaller crystal (usually less than $200 \mu \mathrm{m}$ ) is observed in the central part.

Most cuboids from diverse deposits show fibrous structure. In some cases the crystals have a central core. There are distinct cube growth sectors, between which, in some cases, the deorientation of the crystal lattice is more than between fibers within a separate sector. As a rule cuboids do not show luminescence on a CL-image. An exception is the crystals whose central part is a rounded crystal of earlier generation. Zonal and sectorial structure of some cuboids was revealed by optical examination. Zoning parallel to $\{100\}$ is typically expressed in alternation of zones saturated with microscopic inclusions and zones without inclusions.

Investigations of microdiamonds by FTIR-spectroscopy showed that the predominant type of nitrogen defects for the microdiamonds from the Udachnaya and Sytykanskaya pipes are the defects A and B1. A considerable part of microdiamonds (35\%) content hydrogen (lines 3107 and 1405 in IR spectrum).

Analysis of the data obtained shows that there is a great diversity in composition and degree of nitrogen aggregation among the microdiamonds from the Udachnaya and Sytykanskaya pipes. Thus, various morphological groups show different $\mathrm{A} / \mathrm{B}$ ratios in their infrared absorption spectra.of The proportion of nitrogen-free crystals of type II is the same among octahedrons and dodecahedroids and amounts about $4 \%$, while no type II crystals are found among cuboids. The type II octahedral crystals are, as a rule, of block structure.

The cuboids from the Udachnaya pipe contain more $\mathrm{N}$ than other morphological types. The predominant part of the cuboids belong to the pure type laA. The cuboids containing some defects $\mathrm{B} 1$ have a central core in the form of octahedron.

On recalculation to concentration, differences are revealed in total content of nitrogen in separate zones of microcrystals as well as aggregation state. Differences in IR spectra of central and peripheral zones are distinctly expressed for the octahedral microcrystals from kimberlite pipes. The percentage of B1 centers relative to A-centers is nearly always less on the periphery. An exception is those rare crystals where the central part is type II. In some cases the difference is expressed in the presence or absence hydrogen impurities. As noticed above, some cuboids have zoning caused by microinclusion-saturated domains in their central parts. The spectrums of these zones contain a series of bands whose appearance in diamonds is explained by the presence of admixed water $(3420,1640 \mathrm{~cm}-1)$ and carbonates $(1430$, $880 \mathrm{~cm}-1)$.

The presence of water and carbonate admixtures is also established on examination of microdiamonds $(80-140 \mathrm{~m})$ from the garnet pyroxenites of the Kokchetav Massif. All the crystals investigated belong to type $\mathrm{Ib}-\mathrm{IaA}$ (IaA varies from 48 to $69 \%$ ). At the same time the diamonds from the alluvium placer of the Kokchetav Massif contain neither water nor carbonates, while the $\mathrm{N}$ content may reach $3770 \mathrm{ppm}$.

On the basis of the degree of aggregation of $\mathrm{N}$ atoms in the diamond structure, an attempt was made to estimate the duration of the diamonds' exposure to high temperatures. The figure 2 applied shows that the octahedra and dodecahedroids occupy a wide domain, and this fact may be explained either by polygenic nature of these microdiamond varieties or by a possible effect of growth conditions on the degree of $\mathrm{N}$ aggregation in diamond. 


\section{Udachnaya pipe}

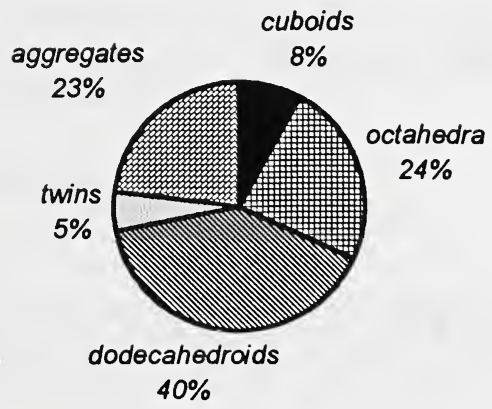

\section{Sytykanskaya pipe}

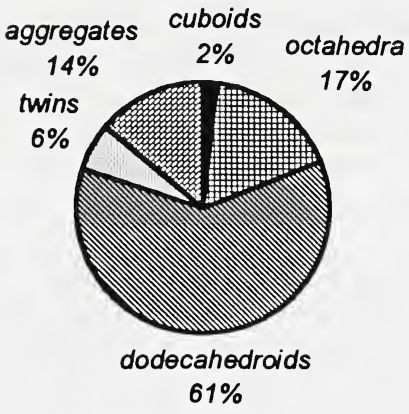

Fig.1 Graphs showing frequencies of appearance of different habits of microdiamonds from Udachnaya and Sytykanskaya kimberlite pipes

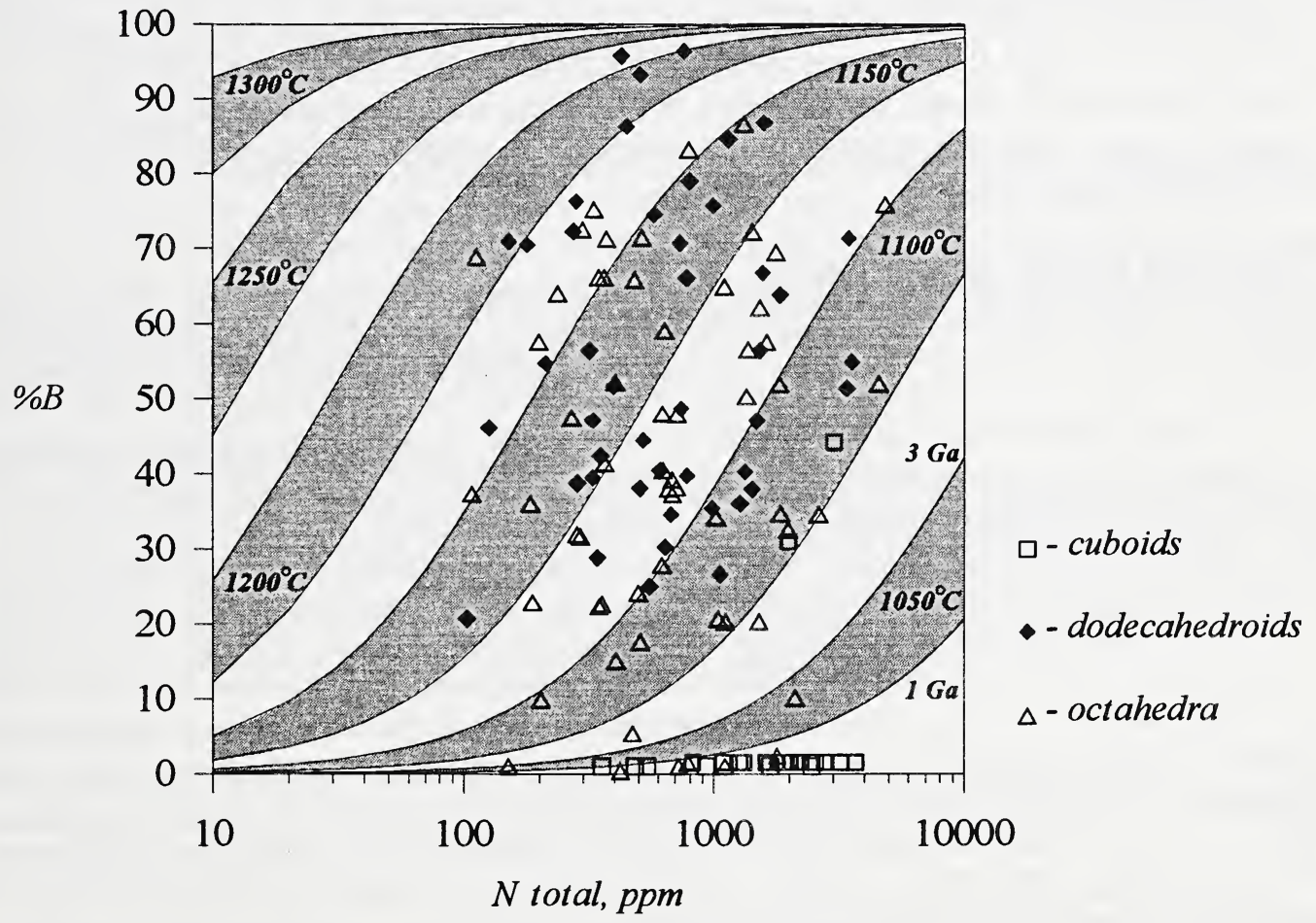

Fig.2 Nitrogen content versus aggregation state for microdiamonds from Udachnaya and Sytykanskaya kimberlite pipes 